\title{
Quality of life and utility decrement associated with Clostridium difficile infection in a French hospital setting
}

\author{
Frédéric Barbut ${ }^{1,2 *}$, Tatiana Galperine ${ }^{3}$, Philippe Vanhems ${ }^{4}$, Alban Le Monnier ${ }^{5}$, Bernard Durand-Gasselin ${ }^{6}$, \\ Frédérique Canis ${ }^{7}$, Viviane Jeanbat ${ }^{8}$, Anne Duburcq $^{8}$, Sarah Alami ${ }^{9}$, Caroline Bensoussan ${ }^{9}$ and Francis Fagnani ${ }^{8}$
}

\begin{abstract}
Background: Clostridium difficile infection (CDI) is associated with a substantial Quality of life impact on patients that has not been so far measured with a generic validated instrument.

Methods: A prospective study was performed in 7 French acute-care settings in patients presenting with a bacteriologically-confirmed CDI. The EQ-5D-3 $L$ was filled in by patients at $7 \pm 2$ days after CDI diagnosis to describe their state of health at that date as well as their state of health immediately before the CDI episode (baseline). Individual utility decrement was obtained by subtracting the corresponding utilities. The Quality Adjusted Life Year (QALY) loss was calculated by multiplying the days spent from baseline to the date of the interview, by the decrement of utility. A multivariate analysis of variance of the utility decrement according to CDI and patients characteristics was performed.
\end{abstract}

Results: Eighty patients were enrolled (mean age: 69.4 years, 55\% females). The utility scores dropped from a mean 0.542 (SD: 0.391 ) at baseline to 0.050 (SD: 0.404) during the CDI episode with a mean adjusted utility decrement of 0.492 (SD: 0.398) point. This decrement increased significantly with CDI severity (Zar score $\geq 3)(p=0.001)$, in patients with a positive baseline utility $(p=0.032)$, in women as compared to men $(p=0.041)$ and in patients aged more than 65 years $(p=0.041)$. No association with the Charlson index was found. The associated QALY loss not integrating the excess mortality was 0.028 (SD: 0.053).

Conclusions: The impact on quality of life of CDI episodes is major and translates in a substantial QALY loss despite their short duration.

Keywords: Clostridium difficile, Health-related quality of life, EQ-5D, France

\section{Background}

Clostridium difficile is an anaerobic Gram-positive bacterium responsible for $15-25 \%$ of cases of post-antibiotic diarrhea and virtually all cases of pseudomembranous colitis $[1,2]$. It is also the main causative agent of nosocomial diarrhea among hospital inpatients [3]. Clinically, C. difficile infection (CDI) ranges from uncomplicated diarrhea to fulminant, and sometimes fatal, pseudomembranous colitis. The estimated

* Correspondence: frederic.barbut@aphp.fr

${ }^{1}$ National Reference Laboratory for Clostridium difficile, Hôpital Saint-Antoine, 34 rue Crozatier, 75012 Paris, France

Université Paris Descartes, UMR-S1139, Sorbonne Paris Cité, Paris, France

Full list of author information is available at the end of the article all-cause 30-day mortality rate among patients who acquire $\mathrm{CDI}$ in healthcare facilities is between 3 and 30\% overall $[4,5]$.

Different therapeutic options are already available and new treatments are currently in development raising the question of defining the best strategies for managing this infection at first episode as well as further recurrences. For this purpose, various economic studies have been performed to document alternative strategies of CDI treatment in terms of cost utility performances [6-14]. These studies include an expression of the benefit to patients based on utility and quality-adjusted life year (QALY) measurement as defined by international recommendations $[15,16]$. Utilities for patients presenting

(c) The Author(s). 2019 Open Access This article is distributed under the terms of the Creative Commons Attribution 4.0 International License (http://creativecommons.org/licenses/by/4.0/), which permits unrestricted use, distribution, and reproduction in any medium, provided you give appropriate credit to the original author(s) and the source, provide a link to the Creative Commons license, and indicate if changes were made. The Creative Commons Public Domain Dedication waiver (http://creativecommons.org/publicdomain/zero/1.0/) applies to the data made available in this article, unless otherwise stated. 
with CDI are poorly documented and are mainly derived from other conditions especially non-infectious diarrhea such as adverse events from oncology treatments [17] and chronic inflammatory bowel disease [18]. This study aims to provide a direct measurement on the utility decrement associated with the CDI infection in French hospital facilities.

\section{Method}

\section{Study population}

This is an observational prospective study performed in 7 French acute-care facilities located in Paris, Lyon, Lille and Valenciennes, 4 of which were large University Hospitals. The recruitment period was over the calendar year of 2016. Patient selection criteria were the following: adult (age $>18$ years) inpatients presenting with a bacteriologically confirmed diagnosis of CDI during a stay in one of the participating hospitals for any clinical causes, accepting to participate and having given an informed consent. Patients presenting with chronic inflammatory bowel disease, involved in an on-going clinical study or unable to fill out a questionnaire for any linguistic or cognitive reasons were excluded. All cases were identified by the bacteriologists that established the CDI diagnosis in each participating facility.

\section{Data collection}

The bacteriologist informed the interviewer in charge of the study of each case. The interviewer then met with patients to explain the study and ask for their informed consent in case they met the selection criteria. Patients were asked to fill out the EQ-5D-3 L [19] to describe their present state of health at the moment of the CDI episode ( $7 \pm 2$ days after diagnosis). Due to difficulties in arranging a new appointment with the patient after resolution of the current CDI episode because of hospital discharge or patient's death, a retrospective assessment of the patients' overall perception of health before the episode was also performed. Patients were asked to use the same instrument to describe retrospectively their state of health immediately before the present CDI episode (baseline). In the EQ-5D-3 L, the health status is described by ticking off one of three levels of functioning ("no problems", "some problems" and "extreme problems") on five dimensions: mobility, self-care, usual activities, pain/discomfort and anxiety/depression. Using a set of weights (value set or so called tariff) for each level of functioning in each dimension, the descriptive information can be converted into a single utility score. Since this study was conducted in France, the French value set was used to calculate utility scores [20]. Patients were also asked to rate their overall perception of health on the EQ-5D-3 L Visual Analog Scale (EQ-VAS), which ranges from 0 (worst imaginable health state) to 100 (best imaginable health state). All relevant clinical data were collected from the patients' records: primary and secondary diagnoses as coded in the Hospital Discharge Database, length of stay, stay in ICU, immunosuppression, presence of any CDI episode within the previous 2-year period and all clinical data needed to characterize the severity of CDI episode. A classical measure of CDI severity is the Zar score which ranges from 0 to 6 (6 indicating the most important severity) [21]. This score is calculated by attributing one point to each of the following items: age $>60$ years, temperature $>38.3^{\circ} \mathrm{C}$, albumin level $<2.5 \mathrm{mg} / \mathrm{dL}$, or peripheral White Blood Cell count $>15,000$ cells $/ \mathrm{mm} 3$ within $48 \mathrm{~h}$ of enrollment. Two points are given for endoscopic evidence of pseudomembranous colitis or treatment in the intensive care unit. Patients with 2 points or more are considered by clinicians to have severe CDI.

Regarding comorbidity, a revised version of the Charlson index [22, 23], based on the ICD-10 coding of primary and secondary diagnoses recorded in the hospital discharge database was used. This index is calculated on the basis of the presence or absence of 17 comorbidities weighted according to their potential influence on mortality. Immunosuppression was considered present for patients with a concomitant immunosuppressive treatment; chemotherapy or radiotherapy; corticosteroid therapy for 30 days or more or at high doses $(>5 \mathrm{mg} / \mathrm{kg}$ prednisolone $>5$ days); and/or presence of blood disease, metastatic cancer, or HIV infection with CD $4<500 / \mathrm{mm}$.

\section{Statistical analysis}

Mean and SD for utility scores and EQ-VAS were calculated at the time of the CDI episode and at baseline. The decrement of utility scores for each patient was calculated by subtracting the current utility score from the baseline value. No adjustment for missing data in the EQ-5D was performed. It was tested whether the decrements of score were respectively dependent on the following categorical factors (Student $\mathrm{t}$-test): age $(<65$ years versus $\geq 65$ years), gender $(\mathrm{M} / \mathrm{F})$, severity of the episode (Zar score $\geq 3$ versus $<3$ ), presence of previous CDI episodes (yes/no), Charlson index ( $<3$ versus $\geq 3$ ), EQ- 5 D at baseline (negative versus positive), presence of immunosuppression (yes/no). A multivariate linear regression analysis was performed using the SAS (SAS V9.3) procedure PROC GLM to analyze the overall effect of these categorical variables. All variables were included simultaneously in the model without any option of automatic selection. The number of Quality Adjusted Days (QALDs) lost due to the CDI episode was calculated by multiplying the number of days from baseline (first symptoms) to the date of the interview by the decrement of utility. Quality Adjusted Years (QALYs) were calculated by dividing QALDs by 365 . 


\section{Results}

\section{Population and CDI episodes characteristics}

A total of 80 patients were included. Three patients died during hospital stay (for causes other than CDI) after having completed the survey and their data were included in the analysis. The population had a mean age of 69.4 years (SD: 14.5) and 55\% were women. The characteristics of their hospital stays are presented in Table 1.

The CDI was coded as primary diagnosis in $22.8 \%$ of cases indicating that it was the reason for the patient's admission to the hospital. Other primary diagnoses were very diverse, the three most frequent being congestive heart failure (19 patients, $23.8 \%$ ), chronic pulmonary disease (16 patients, 20.0\%) and diabetes mellitus (14 patients, $17.5 \%$ ). The mean Charlson index was 5.1 (SD: 2.8 ) with a percentage of $60 \%$ of patients being $\geq 5$

Table 1 Characteristics of the CDI episodes of the sample of 80 patients

\begin{tabular}{|c|c|}
\hline & $\mathrm{n}(\%)$ \\
\hline $\begin{array}{l}\text { Patients with a first episode of CDI } \\
\text { Patients with previous episode (s) }\end{array}$ & $\begin{array}{l}68(85.0 \%) \\
12(15.0 \%)\end{array}$ \\
\hline \multicolumn{2}{|c|}{ Number of previous CDI episodes during the last 2 years $(n=12)$} \\
\hline Mean (SD) & $2.0(1.7)$ \\
\hline Median / Min / Max & $1 / 1 / 5$ \\
\hline At least 1 episode in the last 6 months & $9(75.0 \%)$ \\
\hline Presence of a pseudo-membranous colitis & $3(3.8 \%)$ \\
\hline $\begin{array}{l}\text { Treated in ICU (n, \%) } \\
\text { Death during the hospital stay (n, \%) }\end{array}$ & $\begin{array}{l}2(2.5 \%) \\
3(3.8 \%)\end{array}$ \\
\hline \multicolumn{2}{|l|}{ Zar score of CDI severity } \\
\hline 0 & $13(16.3 \%)$ \\
\hline 1 & $41(51.3 \%)$ \\
\hline 2 & $15(18.8 \%)$ \\
\hline 3 & $9(11.3 \%)$ \\
\hline$\geq 4$ & $2(2.5 \%)$ \\
\hline Presence of immunosuppression & $29(36.3 \%)$ \\
\hline \multicolumn{2}{|l|}{ Number of stools per day at CDI diagnosis } \\
\hline Mean (SD) & $6.3(3.9)$ \\
\hline Median / Min / Max & $5 / 1 / 20$ \\
\hline \multicolumn{2}{|c|}{ Treatments prescribed for CDI (multiple responses possible) } \\
\hline Metronidazole (n (\%)) & $55(68.8 \%)$ \\
\hline Vancomycin (n (\%)) & $27(33.8 \%)$ \\
\hline Fidaxomicin (n (\%)) & $10(12.5 \%)$ \\
\hline \multicolumn{2}{|l|}{ Length of stay (days) } \\
\hline Mean (SD) & $30.3(29.4)$ \\
\hline Median / Min / Max & $19.0 / 2.0 / 149.0$ \\
\hline \multicolumn{2}{|c|}{ Time elapsed between admission and CDI onset (days) } \\
\hline Mean (SD) & $13.2(19.7)$ \\
\hline Median / Min / Max & $4.0 / 0 / 109$ \\
\hline
\end{tabular}

indicating a high risk of mortality associated with severe comorbidities. Three patients died after a mean of 34 days (SD: 22.1) spent in hospital and 2 of them were treated in the ICU for their CDI.

The characteristics of the CDI episodes are displayed in Table 1 . The CDI episode was considered as clinically severe for $32.5 \%$ of patients according to the Zar score (score $\geq 2$ ). The number of stools per day may be also used as a severity indicator. At diagnosis, patients declared a mean number of 6.3 stools/day (up to 20 for one patient) and $88.6 \%$ of patients had more than 3 stools/day. At the date of EQ-5D-3 L completion, these figures were reduced to 2.4 stools/day in average and $38.5 \%$ of patients had $>3$ stools/day.

\section{Quality of life and utility}

The EQ-5D-3 L instrument, including the associated EQ-VAS, was administered on average 6.6 days (SD: 1.6) after CDI bacteriological diagnosis but 19.1 days (SD: 21.3) after the onset of symptoms (according to patient declaration), with a median of 12.0 days (min 3 days / max 124 days), among the 74 patients with no missing data. Additional file 1: Table S1 presents the answers to the 5 sub-scales as completed by the participants with the left column corresponding to the retrospective assessment of their health state before the occurrence of the current CDI episode (baseline) and the right column corresponding to their assessment at the day of interview.

The answers to the EQ-5D-3 L at baseline suggest that patients were already presenting with a severe condition having a substantial impact on their quality of life. A proportion of $34.5 \%$ of them reported at least one important or extreme problem (level 3) among the 5 dimensions of the questionnaire, especially anxiety/ depression (12.5\%), inability to perform usual activities (11.4\%) and pain/discomfort (11.3\%). This proportion increased to $68.7 \%$ during the CDI episode, with 5 patients mentioning the most extreme impact on all 5 dimensions. Pain/discomfort was rated extreme in almost half of the population (48.8\%), inability to perform usual activities and confinement to bed was also very frequently reported ( 43 and $40 \%$ respectively).

Table 2 shows the utility measures obtained from the EQ-5D-3 L at baseline and during the current episode. Utility scores dropped from 0.542 (SD: 0.391) at baseline to 0.050 (SD: 0.404) during the CDI episode. Utility scores at baseline were negative in 14 patients (18\%) with a mean of -0.086 (SD: 0.075 ) and the number of patients that considered themselves with a perfect state of health (utility 1) was only 11 (13.9\% of all). During the episode, utility scores were negative in 43 patients (54.4\%) with a mean of -0.266 (SD: 0.162 ) and positive 
Table 2 Utility scores and utility decrement

\begin{tabular}{lll}
\hline & Before the episode & During the episode \\
\hline EQ-5D score (utility) & & 79 \\
Number of patients with no missing data (+) & 79 & $0.050(0.404)$ \\
Mean (SD) & $0.542(0.391)$ & $-0.052 /-0.530 / 0.888$ \\
Median / Min / Max & $0.632 /-0.263 / 1.000$ & $-0.293 / 0.365$ \\
Quartile 25 / Quartile 75 & $0.270 / 0.888$ & \\
Utility decrement associated with CDI & & $78(97.5 \%)$ \\
Number of patients with no missing data (+) & $-0.492(0.398)$ & $-0.476 /-1.416 / 0.750$ \\
Mean (SD) & $-0.743 /-0.212$ & \\
Median / Min / Max & &
\end{tabular}

(+) missing data in the EQ-5D filled out at baseline in one patient and during the episode in another patient

in the rest of the population with a mean utility score of 0.427 (SD: 0.249).

The mean utility decrement associated with the CDI episode measured in the 78 patients with no missing data was 0.492 points (SD: 0.398 ) with a maximum value of 0.750 and a minimum of -1.416 in one patient (utility gain). It may be worth noticing that such a gain was observed in 5 patients indicating an improvement of their score at the moment of completion of the self-questionnaire compared to baseline.

At baseline, patients rated their state of health on the EQ-VAS instrument at a mean score of 61.0 (SD: 23.0), that dropped to 35.2 (SD: 19.8) during the episode i.e. a decrement of 25.8 (SD: 23.0) points.

\section{Factors associated with utility decrement}

The utility decrement from baseline showed statistically significant increases according to the following characteristics of patients: Zar score of severity $\geq 3(p=0.001)$, a positive utility score at baseline $(p=0.032)$, being a woman $(p=0.041)$ and having an age $>65$ years $(p=$ 0.041) (Table 3). Conversely, the Charlson index, the presence of immuno-suppression or existence of a recurrence did not significantly modify this decrement. The same analyses performed with the EQ-VAS score were only significant for the Zar score of severity $(p=0.0189)$. The SAS procedure PROC GLM was used with the same variables on the utility decrement with a global statistical significance $(p=0.0025)$ (Table 4$)$. It confirmed the previously documented results with the exception of the effect of gender which was no longer significant.

\section{QALYs lost due to CDI}

Assuming that the health-related quality of life as measured by the EQ-5D-3 L was stable during the CDI episode from symptoms onset until the end of treatment, it is possible to derive from these results an estimate of the utility loss associated with a CDI episode. The result obtained in the 74 patients with no missing data was 10.22 QALD (Quality-Adjusted Life Days) (SD: 19.44) or 0.028 QALY (SD: 0.053). By restricting the calculation to patients with less than 60 days of diarrhea $(n=72)$, the results are 7.2 QALD (SD: 7.41) or 0.020 QALY. These estimates did not include the QALY loss due to the excess mortality associated with CDI which should be estimated from external sources [5].

Table 3 Univariate analysis of the EQ-5D decrement and categorical variables

\begin{tabular}{|c|c|c|c|c|}
\hline & $n$ & Mean & SD & $P$-value \\
\hline Gender & & & & 0.041 \\
\hline Male & 36 & 0.393 & 0.380 & \\
\hline Female & 44 & 0.577 & 0.397 & \\
\hline Age & & & & 0.041 \\
\hline$<65$ years & 32 & 0.380 & 0.412 & \\
\hline$\geq 65$ years & 48 & 0.567 & 0.374 & \\
\hline Recurrence & & & & 0.893 \\
\hline No & 68 & 0.490 & 0.399 & \\
\hline Yes & 12 & 0.507 & 0.407 & \\
\hline Immunosuppression & & & & 0.234 \\
\hline No & 50 & 0.539 & 0.374 & \\
\hline Yes & 29 & 0.428 & 0.431 & \\
\hline Charlson score & & & & 0.937 \\
\hline$<5$ & 32 & 0.488 & 0421 & \\
\hline$\geq 5$ & 48 & 0.495 & 0.386 & \\
\hline Zar score & & & & 0.001 \\
\hline$<3$ & 69 & 0.434 & 0.383 & \\
\hline$\geq 3$ & 11 & 0.849 & 0.290 & \\
\hline EQ-5D at baseline & & & & 0.032 \\
\hline$<0$ & 15 & 0.296 & 0.181 & \\
\hline$\geq 0$ & 64 & 0.539 & 0.421 & \\
\hline
\end{tabular}


Table 4 Regression analysis of patient and CDI characteristics with utility decrement as the outcome variable

\begin{tabular}{lllll}
\hline Variable (reference) & Estimate & $95 \% \mathrm{LL}$ & $95 \% \mathrm{UL}$ & $P$-value \\
\hline Gender (male) & -0.100 & -0.2668 & 0.0664 & 0.2347 \\
Age ( $\geq 65$ years) & 0.240 & 0.0229 & 0.4579 & 0.0308 \\
Recurrence (No) & -0.042 & -0.279 & 0.194 & 0.7217 \\
Immunosuppression (No) & 0.0072 & -0183 & 0.198 & 0.9398 \\
Charlson score ( $\geq 5)$ & -0.076 & -0.288 & 0.135 & 0.4730 \\
Zar score (<3) & -0.374 & -0.609 & -0.138 & 0.0023 \\
EQ-5D at baseline $(<0)$ & -0.210 & -0.423 & 0.003 & 0.0535
\end{tabular}

LL lower limit, UL upper limit

\section{Discussion}

This study is among one of the first attempts to directly measure the utility decrement associated with CDI among a sample of patients presenting with this infection. Another study was conducted in a UK sample of 30 patients hospitalized with CDI [24]. A different approach was used as the EQ-5D scores in the CDI patients were compared to the reference value for patients of similar age in the UK general population. The mean score index during the CDI episode was much higher in this UK sample than in this study (0.42 versus 0.05$)$ suggesting that our sample of patients suffered from much more severe infections and/or more severe comorbidities. As very limited data were presented about the clinical characteristics of the UK sample, it is not possible to elaborate further on this comparison. Another striking obstacle in the comparison concerns the fact that different value sets (UK versus France) were used in these two studies. From a general methodological standpoint, it seems however questionable to directly derive a utility decrement of CDI from a comparison to a general population sample as it is highly uncertain to know whether this difference is attributable to CDI itself or to the effects of hospitalization and associated co-morbidities. The clinical characteristics of our sample suggested the presence of severe comorbidities even in patients hospitalized for their CDI episode. It is anticipated that the memory bias associated with a retrospective assessment of the EQ-5D at baseline had fewer limitations in this estimation than using a general population comparison [25]. Other observational studies have explored the importance of memory bias associated with retrospective assessment of Health-Related Quality of Life as compared to general population reference especially in the case of acute-onset injury or illness [26]. Even by using assessment over a retrospective period of 1 year, the authors suggested that retrospective evaluation of health status was more appropriate than the application of population norms to estimate health status prior to acute-onset injury or illness, although there may be a small upward bias in such measurements. In this study, the baseline health state, defined as the period immediately before CDI symptoms onset, occurred only 19.1 days on average prior to the date of the interview and this duration was not correlated with the utility decrement.

A specific CDI health-related quality of life instrument (HRQoL), adapted from the SF-36 instrument, has been recently developed but without results that could be translated in terms of utility decrement [27]. Such disease-specific instruments are designed to detect even small changes in the patient's HRQoL. However, health economists prefer to use generic instruments because they enable the comparison of health states as well as the benefits of medical interventions across diseases. Most published cost-effectiveness models about alternative treatments of CDI have used proxies based on analog situations, especially GI tract diseases. A few studies have actually analyzed the HRQoL impact of GI tract disease with associated diarrhea. In Sweden, a study was performed in 116 patients presenting with collagenous colitis with the SF-36 questionnaire. Patients with active disease ( $\geq 3$ stools/day or $>1$ liquid stool/day) scored worse HRQoL than patients in remission [28]. Another study [29] was performed in 592 Inflammatory Bowel Disease (IBD) patients treated in six Hungarian tertiary centers using the SF-36 questionnaire and observed similar results regarding a significant association between the SF-36 score and disease activity $(p<0.001)$. Diarrhea was perceived as the most severe symptom during the course of the disease. Similarly, Stark et al. [18], in a German study using the EQ-5D on 447 patients presenting with IBD, showed that patients in remission had a significantly higher utility score than with active disease: 0.95 (SD: 0.08 ) versus 0.75 (SD: 0.25) in Crohn's disease $(p<0.0001)$ and 0.96 (SD: 0.08$)$ versus 0.84 (SD: 0.15) $(p<0.0001)$ in ulcerative colitis. Similar results have been published in patients presenting with Irritable Bowel Syndrome (IBS). In the study by Wang et al. [30], the mean EQ-5D index score was 0.739 for IBS and 0.854 for non-IBS. After adjustment for age, gender and presence of significant illnesses in another family member of the participant, the effect of IBS on the EQ-5D still showed a significant difference $[-0.11$ (95\% CI: -0.15 to -0.07$), p<0.001]$. In the Canavan study [31], the median overall utility score for the cohort before seeing a gastroenterologist was 0.76 (interquartile range: 0.69 to 0.80 ). These results are however not fully comparable to those obtained in hospitalized patients presenting with CDI occurring on top of severe comorbidities.

Another therapeutic domain of reference for this external comparison concerns the HRQoL impact of diarrhea as an adverse event (AE) of oncology treatments, a condition well documented in clinical trials with a 
standardized grading of severity [32]. A recent review was published [15] identifying two studies performed in the UK [33] and Japan [34] which included diarrhea in their scope. Both studies used short descriptions (vignettes) of the AEs of interest to obtain utility values for chemotherapy-related AEs by surveying small samples of the general public about their preferences (using a Time-Trade-Off approach) among the different health states described in the vignettes including the presence/ absence of diarrhea of various severities. The results obtained in terms of utility decrement were in the range of 0.07-0.08. A similar study was performed in the UK among 100 members of the general public to elicit utilities for radioactive iodine-refractory differentiated thyroid cancer and evaluate the impact of treatment response and toxicities on HRQoL [35]. The authors found a mean utility for diarrhea of $0.42(0.29)$ with an adjusted utility decrement of 0.47 (95\% CI: 0.52-0.41). They noticed that it was perceived as the most burdensome health state among all other AEs presented. These values were however lower than previous estimates from vignette studies conducted in other malignancies. In metastatic renal cell carcinoma, a study reported a mean utility of 0.53 for grade III diarrhea [36]. Other studies in metastatic breast cancer and non-small-cell lung cancer reported values of 0.61 and 0.6 respectively $[37,38]$. These differences may be the consequences of variation in the health state descriptions used between studies or differences in the population samples resulting in difficulties in comparing the values directly.

Another aspect that makes these evaluations difficult is that CDIs analogous to other clinical states with diarrhea are transient. This feature is important to consider in all studies performed by interviewing a sample of the general public and may generate a bias because methods designed to capture the preferences for transient health states may not conform to the axiom of constant proportional trade-off as the duration of the health state may affect valuation [39]. This limitation applies also in part in our study. This possible bias does not concern the patients with CDI who are fully aware of the fact that their infection is a transient state. It concerns the utilization of the tariff derived from a general population survey where the vignettes submitted did not include the dimension of the likely time spent in the health states. The negative utility decrement (utility gain) observed among 5 patients may be explained either by the improvement of their CDI symptoms, or by the resolution of their comorbidity or both.

The sample size of our study was limited due to the difficulty of implementing the protocol. Some of our results should therefore be interpreted with caution. This applies especially to our analysis about the factors affecting utility decrement. The absence of a statistically significant difference between patients presenting with recurrence or first episode could for example be explained by a lack of statistical power.

\section{Conclusion}

The impact on quality of life of CDI episodes aside from the consequence of excess mortality is major and translates in a substantial QALY loss despite their short duration.

\section{Additional file}

Additional file 1: Table S1. EQ-5D-3 $\mathrm{L}$ results ( $n=80$ patients) (DOCX $34 \mathrm{~kb}$ )

\section{Acknowledgments}

We acknowledge the help of N. Khanafer and L. Oltra for their contribution to data collection.

\section{Funding}

This work was supported by an unrestricted grant from MSD France.

\section{Availability of data and materials}

The datasets generated and analyzed during the current study are available from the corresponding author on reasonable request.

\section{Authors' contributions}

FB, TG, PV, ALM, BD-G and FC designed the study and organized data collection in their facilities; $S A, C B, A D$ and VJ conducted the research; $A D$ and FF carried out the data analysis; FF drafted the manuscript. All authors read and approved the final manuscript.

\section{Ethics approval and consent to participate}

The protocol of the study was approved by an institutional review committee (Comité de Protection des Personnes, St Antoine Hospital, March 16, 2015) and by the Commission Nationale Informatique et Liberté (CNIL) on August 10, 2015. In accordance with this approval, consent to participate was obtained from patients who met all selection criteria.

Consent for publication

Not applicable

Competing interests

SA and CB are employees of MSD France. VJ, AD and FF are employees of CEMKA.

\section{Publisher's Note}

Springer Nature remains neutral with regard to jurisdictional claims in published maps and institutional affiliations.

\section{Author details}

${ }^{1}$ National Reference Laboratory for Clostridium difficile, Hôpital Saint-Antoine, 34 rue Crozatier, 75012 Paris, France. ' Université Paris Descartes, UMR-S1139, Sorbonne Paris Cité, Paris, France. ${ }^{3} \mathrm{CHRU}$ Lille, Maladies Infectieuses, French Group of Faecal Microbiota Transplantation (GFTF), Lille, France.

${ }^{4}$ Groupement Hospitalier Edouard Herriot, Unité d'Hygiène, Epidémiologie et Prévention, Hospices Civils de Lyon, and Université Lyon 1, Lyon, France.

${ }^{5}$ Laboratoire de Microbiologie Clinique, GH Paris Saint-Joseph, Paris, France.

${ }^{6}$ Hôpital Léopold Bellan, Service de gériatrie and Fondation Hospitalière Ste Marie Service de Soins de Suite et de Réadaptation gérontologique, Paris, France. ${ }^{7}$ Centre hospitalier de Valenciennes, UF de Microbiologie, Pôle de Biologie Médicale, Valenciennes, France. ${ }^{8}$ CEMKA, Bourg la Reine, France. ${ }^{9}$ MSD France, Courbevoie, France. 
Received: 7 May 2018 Accepted: 3 January 2019

Published online: 11 January 2019

\section{References}

1. Rupnik M, Wilcox MH, Gerding DN. Clostridium difficile infection: new developments in epidemiology and pathogenesis. Nat Rev Microbiol. 2009; 7:52-36.

2. Bartlett JG, Gerding DN. Clinical recognition and diagnosis of Clostridium difficile infection. Clin Infect Dis. 2008:46:S12-8.

3. Lessa FC, Winston LG, McDonald LC, Emerging Infections Program C. difficile Surveillance Team. Burden of Clostridium difficile infection in the United States. N Engl J Med. 2015;372:2369-70.

4. Wiegand PN, Nathwani D, Wilcox MH, Stephens J, Shelbaya A, Haider S. Clinical and economic burden of Clostridium difficile infection in Europe: a systematic review of healthcare-facility acquired infection. J Hosp Infect. 2012;81:1-14.

5. Schmid D, Kuo HW, Simons E, Kanitz EE, Wenisch J, Allerberger F, et al. Allcause mortality in hospitalized patients with infectious diarrhea: Clostridium difficile versus other enteric pathogens in Austria from 2008 to 2010. J Infect Public Health. 2014;7:133-44.

6. Baro E, Galperine T, Denies F, et al. Cost-effectiveness analysis of five competing strategies for the management of multiple recurrent community-onset Clostridium difficile infection in France. PLoS One. 2017; 12(1):e0170258

7. Konijeti GG, Sauk J, Shrime MG, Gupta M, Ananthakrishnan AN. Costeffectiveness of competing strategies for management of recurrent Clostridium difficile infection: a decision analysis. Clin Infect Dis. 2014;58(11): $1507 \pm 14$.

8. Bartsch SM, Umscheid CA, Fishman N, Lee BY. Is fidaxomicin worth the cost? An economic analysis. Clin Infect Dis. 2013;57(4):555 \pm 61 .

9. Stranges PM, Hutton DW, Collins CD. Cost-effectiveness analysis evaluating fidaxomicin versus oral vancomycin for the treatment of Clostridium difficile

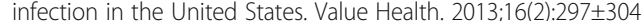

10. Varier RU, Biltaji E, Smith KJ, Roberts MS, Jensen MK, LaFleur J, et al. Costeffectiveness analysis of treatment strategies for initial Clostridium difficile infection. Clin Microbiol Infect. 2014;20(12):1343 \pm 51.

11. Varier RU, Biltaji E, Smith KJ, Roberts MS, Kyle Jensen M, LaFleur J, et al. Costeffectiveness analysis of fecal microbiota transplantation for recurrent Clostridium difficile infection. Infect Control Hosp Epidemiol. 2015;36(4):438_44.

12. Lapointe-Shaw L, Tran KL, Coyte PC, Hancock-Howard RL, Powis J, Poutanen SM, et al. Cost-Effectiveness analysis of six strategies to treat recurrent Clostridium difficile infection. PloS One. 2016;11(2):e0149521.

13. Nathwani D, Cornely OA, Van Engen AK, Odufowora-Sita O, Retsa P, Odeyemi IAO. Cost-effectiveness analysis of fidaxomicin versus vancomycin in Clostridium difficile infection. J Antimicrob Chemother. 2014;69(11):2901 \pm 12

14. Zowall $H$, Brewer $C$, Deutsch $A$. Cost-effectiveness of fecal microbiota transplant in treating Clostridium difficile infection in Canada. Value Health. 2014;17(7):A676

15. Kind P, Lafata JE, Matuszewski K, Raisch D. The use of QALYs in clinical and patient decision-making: issues and prospects. Value Health. 2009;12(Suppl 1):S27-30

16. Whitehead SJ, Ali S. Health outcomes in economic evaluation: the QALY and utilities. Br Med Bull. 2010;96(1):5-21.

17. Shabaruddin FH, Chen LC, Elliott RA, Payne K. A systematic review of utility values for chemotherapy-related adverse events. Pharmaco Economics. 2013;31:277-88.

18. Stark RG, Reitmeir $P$, Leidl $R$, König HH. Validity, reliability, and responsiveness of the EQ-5D in inflammatory bowel disease in Germany. Inflamm Bowel Dis. 2010 Jan;16(1):42-51.

19. The EuroQol Group. EuroQol-a new facility for the measurement of health-related quality of life. Health Policy. 1990;16(3):199-208.

20. Chevalier J, de Pouvourville G. Valuing EQ-5D using time trade-off in France. Eur J Health Econ. 2013;14:57-66.

21. Zar FA, Bakkanagari SR, Moorthi KM, Davis MB. A comparison of vancomycin and metronidazole for the treatment of Clostridium difficile-associated diarrhea, stratified by disease severity. Clin Infect Dis. 2007:45:302-7.

22. Charlson ME, Pompei $\mathrm{P}$, Ales KL, et al. A new method of classifying prognostic comorbidity in longitudinal studies: development and validation J Chronic Dis. 1987;40(5):373-83.

23. Quan H, Li B, Couris CM, Fushimi K, Graham P, Hider P, Januel JM, Sundararajan V. Updating and validating the Charlson comorbidity index and score for risk adjustment in hospital discharge abstracts using data from 6 countries. Am J Epidemiol. 2011:173(6):676-82.

24. Wilcox MH, Ahir H, Coia JE, Dogson A, Hopkins S, Llewlyn MJ, Settle C, Mclain-Smith S, Marcella SW. Impact of recurrent Clostridium difficile infection: hospitalization and patient quality of life. J Antimicrob Chemother 2017;72(9):2647-56.

25. Blome C, Augustin M. Measuring change in quality of life: bias in prospective and retrospective evaluation. Value Health. 2015;18(1):110-5.

26. Ross W, Derrett S, Hansen P, Langley J. Retrospective evaluation versus population norms for the measurement of baseline health status. Health Qual Life Outcomes. 2012;10:68.

27. Garey KW, Aitken SL, Gschwind L, Goddu S, Xie Y, Duff C, Barbut F, Shah DN, DuPont HL. Development and validation of a Clostridium difficile healthrelated quality of life questionnaire. J Clin Gastroenterol. 2016;50:631-7.

28. Hjortswanga $H_{1}$ TyskbC BJ, Benonic C, Vigrenc L, Kilanderd A, Larssond L, Tahae $Y$, Ström M. Health-related quality of life is impaired in active collagenous colitis. Dig Liver Dis. 2011;43:102-9.

29. Horvath G, Farkas K, Hollosi R, Nagy F, Szepes Z, Papp M, Palatka K, Miheller $P$, Lakatos L, Szamosi T, Nyari T, Wittmann T, Molnar T. Is there any association between impaired health-related quality of life and nonadherence to medical therapy in inflammatory bowel disease? Scand J Gastroenterol. 2012:47:1298-303.

30. Wang YT, Lim HY, Tai D, et al. The impact of Irritable Bowel Syndrome on health-related quality of life: a Singapore perspective. BMC Gastroenterol. 2012;12:104

31. Canavan C, West J, Card T. Change in quality of life for patients with irritable bowel syndrome following referral to a gastroenterologist: a cohort study. PLoS One. 2015;10(10):e0139389. https://doi.org/10.1371/journal.pone 0139389.

32. National Cancer Institute. NCl thesaurus adverse event (code C41331). Bethesda: $\mathrm{NCl} ; 2011$.

33. Beusterien KM, Davies J, Leach M, Meiklejohn D, Grinspan JL, O'Toole A, Bramham-Jones S. Population preference values for treatment outcomes in chronic lymphocytic leukaemia: a cross-sectional utility study. Health Qual Life Outcomes. 2010;8:50.

34. Shiroiwa T, Fukuda T, Tsutani K. Health utility scores of colorectal cancer based on societal preference in Japan. Qual Life Res. 2009:18:1095.

35. Fordham BA, Kerr C, de Freitas HM, et al. Health state utility valuation in radioactive iodine-refractory differentiated thyroid cancer. Patient Prefer Adherence. 2015;9:1561-72.

36. Swinburn P, Lloyd A, Nathan P, Choueiri TK, Cella D, Neary MP. Elicitation of health state utilities in metastatic renal cell carcinoma. Curr Med Res Opin. 2010;26(5):1091-6.

37. Lloyd A, Nafees B, Narewska J, Dewilde S, Watkins J. Health state utilities for metastatic breast cancer. Br J Cancer. 2006;95:683-90.

38. Nafees B, Stafford M, Gavriel S, Bhalla S, Watkins J. Health state utilities for non-small cell lung cancer. Health Qual Life Outcomes. 2008;6:84.

39. Wright DR, Wittenberg E, Swan JS, Miksad RA, Prosser LA. Methods for measuring temporary health states for cost-utility analyses. PharmacoEconomics. 2009:27(9):713-23.

Ready to submit your research? Choose BMC and benefit from

- fast, convenient online submission

- thorough peer review by experienced researchers in your field

- rapid publication on acceptance

- support for research data, including large and complex data types

- gold Open Access which fosters wider collaboration and increased citations

- maximum visibility for your research: over $100 \mathrm{M}$ website views per year

At BMC, research is always in progress.

Learn more biomedcentral.com/submission 